EDITOR'S

CHOICE

\title{
Fatal thalamic abscess secondary to dental infection
}

\author{
Shadi Basyuni, ${ }^{1}{ }^{2}$ Valmiki Sharma, ${ }^{1}$ Vijay Santhanam, ${ }^{1}$ Ashley Ferro ${ }^{3}$
}

${ }^{1}$ Department of Maxillofacial Surgery, Addenbrooke's Hospital, Cambridge, UK ${ }^{2}$ University of Cambridge, Cambridge, UK

${ }^{3}$ Addenbrooke's Hospital, Cambridge, UK

\section{Correspondence to}

Dr Shadi Basyuni,

shadi.elbasyuni@

addenbrookes.nhs.uk

Accepted 22 November 2015

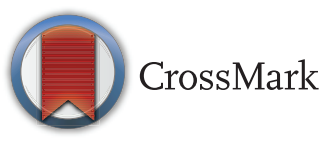

To cite: Basyuni $S$, Sharma V, Santhanam V, et al. BMJ Case Rep Published online: [please include Day Month Year] doi:10.1136/bcr-2015212589

\section{SUMMARY}

We present the case of poor neurological recovery and subsequent death secondary to a thalamic abscess in a 53-year-old man. This patient initially presented with sudden dysarthria and left hemiparesis while driving. Neuroimaging showed a multilobular abscess involving the right thalamus with oedema extending to the basal ganglionic region and brainstem. The source of the abscess was initially unknown and it required draining multiple times while the different causes were being explored. The patient's neurological state along with intubation made for a difficult and inconclusive oral examination. It was only after neuroimaging included tooth-bearing areas that it became evident that this patient had extensive periodontal disease with multiple areas of periapical radiolucencies. The patient underwent complete dental clearance alongside repeated drainage of the abscess. Despite initial postoperative improvement, the patient never recovered from the neurological damage and died 3 weeks later.

\section{BACKGROUND}

Thalamic abscesses are relatively rare, accounting for a minority of all brain abscesses. Dental pathology is a common cause of these abscesses. Eradication of the primary focus is paramount in determining the clinical outcome of patients with cerebral abscesses. However, the paraphernalia in a neurocritical care setting complicates traditional radiological and clinical examination of the oral cavity.

CT of the brain is typically used in the initial assessment of cerebral abscesses and for neurosurgical planning. The tooth-bearing areas of the jaws are often not included in these scans and thus do not offer any information regarding the presence of dental pathology. A coronally reformatted CT that includes the alveolar processes of the mandible and maxilla would offer sufficient information to assess the state of dentition. This should simplify the screening for odontogenic infection in cerebral abscess with no overt cause of sepsis.

\section{CASE PRESENTATION}

A 53-year-old man presented with sudden onset dysarthria and left-sided hemiparesis while driving. MRI and CT imaging showed a multilobular haemorrhagic lesion involving the right thalamus with oedema extending to the brainstem. Following neurological decline, the patient was transferred to a tertiary centre. On arrival at the specialist centre, the patient had a Glasgow Coma Scale score of 14 (E4 V4 M6), which deteriorated significantly shortly afterwards. This necessitated urgent aspiration and biopsy of the lesion.
The patient's medical history was remarkable for diabetes mellitus, secondary to resection of a pituitary adenoma for the treatment of acromegaly. His diabetes was managed with gliclazide and insulin. He was on no other regular medication and had no known drug allergies. It was noted that he was a heavy smoker. Relatives reported no preceding dental pain or infection. He had not had any dental procedures performed recently.

\section{INVESTIGATIONS}

Blood tests on admission showed a raised white cell count $\left(17.9 \times 10^{9} / \mathrm{L}\right)$ and neutrophils $\left(15.86 \times 10^{9} / \mathrm{L}\right)$. Initial CT head and MRI (figures 1 and 2) showed a large peripherally enhancing mass $(43 \mathrm{~mm} \times 37 \mathrm{~mm})$ involving the right internal capsule and thalamus, with extensions to the midbrain. The lesion was surrounded by oedema and there was significant mass effect on the right lateral ventricle.

The patient underwent drainage of the lesion, which confirmed it as an abscess. Pus initially grew Gram-positive cocci, which were later identified as Streptococcus intermedius. Investigations were carried out to identify the primary origin of the abscess. Blood cultures were negative and the chest $\mathrm{X}$-ray was clear. A bedside transthoracic echocardiogram showed no obvious vegetations. Dental radiographs were not possible due to intubation and sedation. Several days later a neck lump was investigated as a putative origin. CT neck showed no enhancing lesion in the suspected area. It was, however, the first time the tooth-bearing regions of the skull were formally imaged. Following reformatting of the CT image (figure 3), it became evident that the patient had extensive periodontal disease with multiple areas of periapical radiolucencies.

After completion of treatment without satisfactory neurological recovery, an MRI was performed to delineate any remaining lesion. This revealed a reduction in size compared with previous imaging, but foci of subacute infarction were detected in the posterior circulation territory bilaterally including the midbrain tegmentum.

\section{DIFFERENTIAL DIAGNOSIS}

The first challenge on presentation was to determine whether the identified lesion was a brain tumour or abscess. The diagnosis of a cerebral abscess became clear following aspiration of pus and culturing of S. intermedius.

After identifying the lesion as an abscess, the second challenge was to find the primary source of the infection. The differentials included common foci of cerebral abscesses (pneumonia, endocarditis and dental infection). Pneumonia and endocarditis 


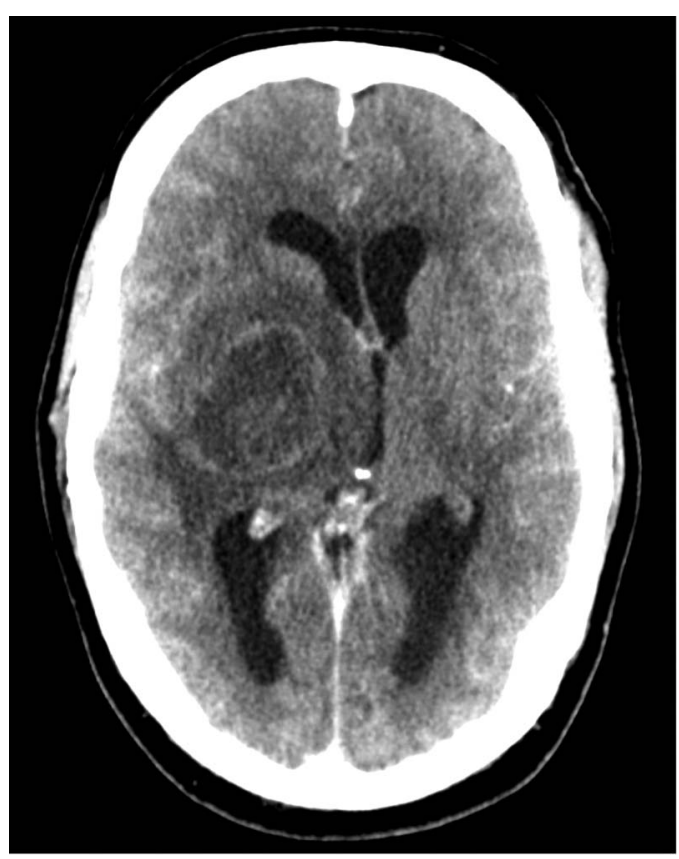

Figure 1 Initial CT of the brain with contrast.

were excluded through negative chest X-ray and transthoracic echocardiography, respectively. The finding of dental pathology (gross periodontal disease with periapical abscess formation) along with the culturing of $S$. intermedius implies that dental infection is probably the primary source of infection. This interpretation of these findings is limited by the absence of genetic analysis to determine the strain of the cultured $S$. intermedius. Restriction enzyme analysis would increase confidence in our interpretation.

\section{TREATMENT}

Following neurological deterioration on the first day of admission, the patient underwent urgent burr hole aspiration and

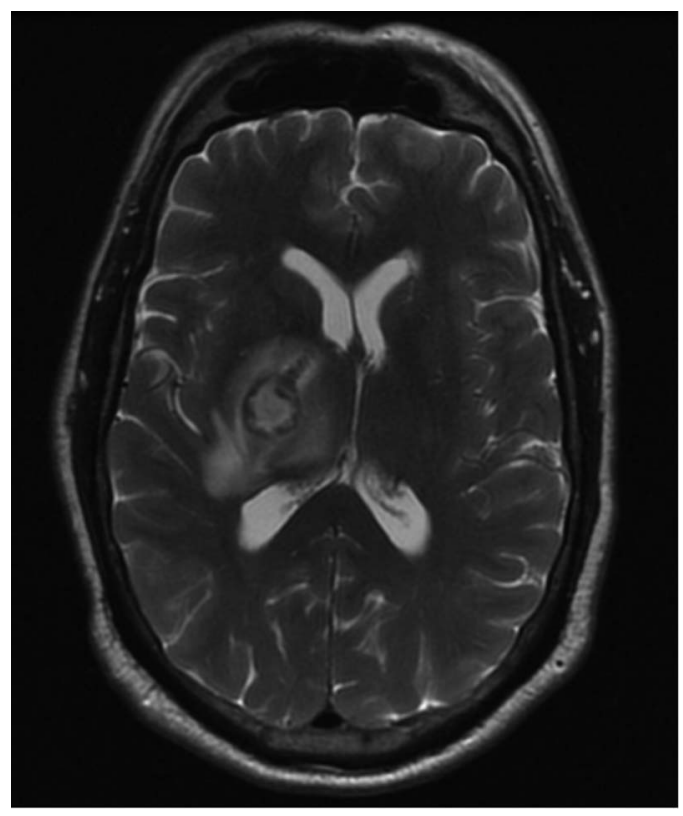

Figure 2 Initial MRI of the brain.

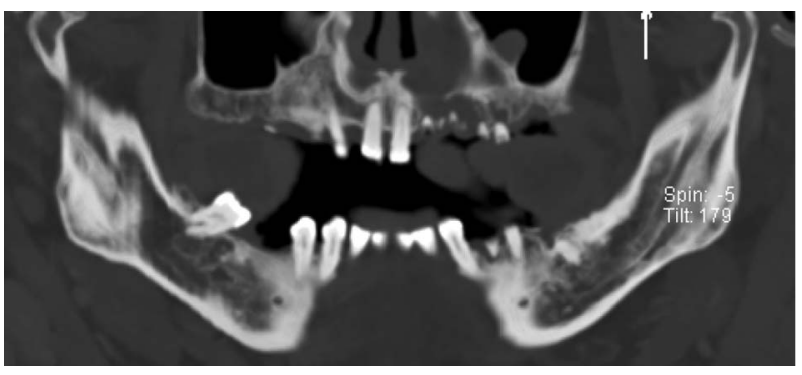

Figure 3 Reformatted CT showing tooth-bearing regions.

biopsy of the lesion. This served as an important diagnostic tool and also aimed to drain the infection and reduce the mass effect. In anticipation of long-term antibiotics, a central catheter was peripherally inserted. The patient was initially given metronidazole and ceftriazone but, following advice from the microbiology department, the patient was switched to meropenem.

Owing to recollection of the abscess and continuing neurological decline, the patient underwent a second aspiration procedure 4 days after the initial drainage. Following the identification of significant periodontal disease, the decision was made to extract the patient's remaining teeth and perform one further drainage procedure.

\section{OUTCOME AND FOLLOW-UP}

Following dental clearance and the final aspiration, a transient mild improvement in neurological state was reported. Unfortunately the patient deteriorated further and the follow-up MRI indicated foci of subacute infarction in the posterior circulation territory. Based on the MRI results, it was believed inconceivable that the patient would make a recovery without devastating disability. In fact, it was felt more probable that the patient would not wake significantly. Curative treatment was therefore ceased and palliation commenced. The patient died 3 weeks later.

\section{DISCUSSION}

Odontogenic sources are increasingly being reported as the origin of brain abscesses. Advances in neuroimaging, antibiotic therapy, microbiological isolation and neurosurgical techniques in recent years have seen a marked improvement in mortality from $40 \%$ to $10 \% .{ }^{1}$ Yet, brain abscesses remain a formidable and potentially life-threatening condition. Early diagnosis and rapid management is fundamental for ensuring good prognosis and preventing complications. ${ }^{2}$ Eradication of the primary focus, however, is essential in determining the clinical outcome of patients. ${ }^{3}$ Indeed, various case reports have reported failure of elimination of brain abscesses without removal of infected teeth. $^{45}$ Thalamic abscesses are particularly rare $(1.3-6 \%$ of all cerebral abscesses) and dental pathology is a recognised cause. ${ }^{6}$

Ewald $e t a l^{7}$ proposed three criteria that must be satisfied to establish the diagnosis of a brain abscess with odontogenic origin: (1) an alternative source of bacteraemia has not been found; (2) microbiological findings are consistent with oral microflora; and (3) there must be clinical or radiographic evidence of dental pathology. In this case all three criteria were fulfilled. S. intermedius is a recognised species of the normal oral microflora and has previously been found in odontogenic abscesses. ${ }^{8}{ }^{9}$ In light of these findings, it seems highly probable that this thalamic abscess was of odontogenic origin. 
Theoretically there are four routes by which odontogenic infections can spread to the brain: haematogenous spread, direct spread via the cavernous sinus, contiguous extension and through lymphatics. Haematogenous spread appears to be the predominant route of propagation, which may explain why there is no predilection for maxillary or mandibular teeth to induce cerebral abscess formation. ${ }^{10}$

Although less sensitive than diffusion-weighted MRI, cranial CT with contrast has become the mainstay of rapid diagnosis of cerebral abscesses, allowing early detection, characterisation and staging of the lesion. ${ }^{11}$ The routine CT brain scan range extends from the top of the C1 lamina inferiorly to the top of the calvarium, thereby excluding the alveolar processes. To allow early exclusion of odontogenic infection as the causative mechanism of cerebral abscess in intubated patients, we suggest extending the scan range of routine preliminary CT in patients with suspected abscess of unidentified origin to include the toothbearing areas of the jaws. Coronal reformatting of the image should provide sufficient information which, when considered with clinical assessment, should allow more reliable screening for odontogenic infections.

\section{Learning points}

- The thalamus is a rare location for cerebral abscesses to form.

- Early eradication of the primary source of infection is paramount in determining the clinical outcome of patients with cerebral abscesses.

- Odontogenic infections should be screened for in cerebral abscesses with no known origin of infection.

- Traditional clinical and radiological examinations may not be possible in the neurocritical care setting.

- An adequately reformatted CT scan that includes the alveolar processes of the mandible and maxilla may be used as an adjunct to clinical examination to screen for odontogenic infections in neurologically compromised patients.
Contributors The idea for the article was provided by VSa and VSh. The literature search was performed by SB and AF. The article was written by SB. The guarantors for the article are SB, VSh and VSa. The case was managed (from a maxillofacial point of view) by VSa.

Competing interests None declared.

Patient consent Obtained.

Provenance and peer review Not commissioned; externally peer reviewed.

\section{REFERENCES}

1 Brouwer MC, Coutinho JM, van de Beek D. Clinical characteristics and outcome of brain abscess: systematic review and meta-analysis. Neurology 2014;82:806-13.

2 Tattevin P, Bruneel F, Clair B, et al. Bacterial brain abscesses: a retrospective study of 94 patients admitted to an intensive care unit (1980 to 1999). Am J Med 2003:115:143-6.

3 Muzumdar D, Jhawar S, Goel A. Brain abscess: an overview. Int I Surg 2011;9:136-44.

4 Aldous JA, Powell GL, Stensaas SS. Brain abscess of odontogenic origin: report of case. J Am Dent Assoc 1987;115:861-3.

5 Clifton TC, Kalamchi $S$. A case of odontogenic brain abscess arising from covert dental sepsis. Ann R Coll Surg Engl 2012;94:e41-3.

6 Lutz TW, Landolt $\mathrm{H}$, Wasner $\mathrm{M}$, et al. Diagnosis and management of abscesses in the basal ganglia and thalamus: a survey. Acta Neurochir (Wien) 1994;127:91-8.

7 Ewald C, Kuhn S, Kalff R. Pyogenic infections of the central nervous system secondary to dental affections-a report of six cases. Neurosurg Rev 2006;29:163-6.

8 Claridge JE III, Attorri S, Musher DM, et al. Streptococcus intermedius, Streptococcus constellatus, and Streptococcus anginosus ("Streptococcus milleri group") are of different clinical importance and are not equally associated with abscess. Clin Infect Dis 2001:32:1511-15.

9 Whiley RA, Beighton D, Winstanley TG, et al. Streptococcus intermedius, Streptococcus constellatus, and Streptococcus anginosus (the Streptococcus milleri group): association with different body sites and clinical infections. J Clin Microbiol 1992;30:243-4

10 Moazzam AA, Rajagopal SM, Sedghizadeh PP, et al. Intracranial bacterial infections of oral origin. J Clin Neurosci 2015;22:800-6.

11 Nguyen JB, Black BR, Leimkuehler MM, et al. Intracranial pyogenic abscess: imaging diagnosis utilizing recent advances in computed tomography and magnetic resonance imaging. Crit Rev Comput Tomogr 2004;45:181-224.

Copyright 2015 BMJ Publishing Group. All rights reserved. For permission to reuse any of this content visit

http://group.bmi.com/group/rights-licensing/permissions.

BMJ Case Report Fellows may re-use this article for personal use and teaching without any further permission.

Become a Fellow of BMJ Case Reports today and you can:

- Submit as many cases as you like

- Enjoy fast sympathetic peer review and rapid publication of accepted articles

- Access all the published articles

- Re-use any of the published material for personal use and teaching without further permission

For information on Institutional Fellowships contact consortiasales@bmjgroup.com

Visit casereports.bmj.com for more articles like this and to become a Fellow 